\title{
Innovative research methods for studying treatments for rare diseases: methodological review
}

\author{
(@) (1) OPEN ACCESS
}

\section{Joshua J Gagne assistant professor, Lauren Thompson research assistant, Kelly O'Keefe research manager, Aaron S Kesselheim assistant professor}

Division of Pharmacoepidemiology and Pharmacoeconomics, Department of Medicine, Brigham and Women's Hospital and Harvard Medical School, Boston, MA

\begin{abstract}
Objective To examine methods for generating evidence on health outcomes in patients with rare diseases.

Design Methodological review of existing literature.

Setting PubMed, Embase, and Academic Search Premier searched for articles describing innovative approaches to randomized trial design and analysis methods and methods for conducting observational research in patients with rare diseases.
\end{abstract}

Main outcome measures We assessed information related to the proposed methods, the specific rare disease being studied, and outcomes from the application of the methods. We summarize methods with respect to their advantages in studying health outcomes in rare diseases and provide examples of their application.

Results We identified 46 articles that proposed or described methods for studying patient health outcomes in rare diseases. Articles covered a wide range of rare diseases and most (72\%) were published in 2008 or later. We identified 16 research strategies for studying rare disease. Innovative clinical trial methods minimize sample size requirements $(n=4)$ and maximize the proportion of patients who receive active treatment $(n=2)$, strategies crucial to studying small populations of patients with limited treatment choices. No studies describing unique methods for conducting observational studies in patients with rare diseases were identified.

Conclusions Though numerous studies apply unique clinical trial designs and considerations to assess patient health outcomes in rare diseases, less attention has been paid to innovative methods for studying rare diseases using observational data.

\section{Introduction}

Though an individual rare disease is by definition uncommon, according to the statutory definitions set in the United States (prevalence $<200000$ people each year; equating to a prevalence of approximately $<64$ per 100000 people) and European Union ( $<50$ per 100000 people), more than 6800 different conditions qualify as rare diseases and 6-8\% of the population is affected. ${ }^{1-3}$ This translates to about 60 million people in the United States and EU alone. Rare diseases comprise a heterogeneous set of conditions that afflict various organ systems, have wide ranging prognoses, and even vary along a gradient of rareness.

Many barriers exist to advancing knowledge of and treatment options for rare diseases. ${ }^{4}$ The small patient populations can dampen commercial interest in development of treatments. Yet even for those rare conditions where funding is plentiful and manufacturers of therapeutics are engaged, methodological and data constraints limit the ability to generate evidence on patient health outcomes. The most obvious challenge to conducting rigorous research is the small number of eligible participants for a given study. In addition, geographic dispersion of patients, lack of knowledge about the clinical course of disease, and lack of appropriate comparator treatments further hinder the generation of evidence. ${ }^{5}$ As a result relatively little is known about the clinical course of many rare diseases and few treatment options exist.

However, there may be pathways for collectively advancing the study of rare diseases. Although rare diseases may present unique clinical problems, the methodological challenges to studying health outcomes are often communal. In recent years, innovative epidemiological and clinical trial methods have been developed that offer promise for promoting more efficient and effective research. Because rare diseases are so clinically dissimilar, clinicians, scientists, and other stakeholders working in one medical specialty may not be familiar with methods being applied in other disciplines. Thus, we conducted a methodological review to catalogue and describe innovative approaches to studying health outcomes in patients with rare diseases. Our goal was to identify innovative approaches to research that have been, or can be, applied to overcome the methodological challenges inherent in the study of rare diseases. 


\section{Methods}

\section{Search strategy}

We searched PubMed, Embase, and Academic Search Premier from their commencement through December 2012 for English language articles that included the following terms: "rare diseases", "orphan drug", "comparative effectiveness", "evidence-based medicine", "health technology assessment", "outcome assessment", "methods", "epidemiology", and "registries". The supplementary file provides details of the search strategies.

We also conducted ad hoc searches of the three reference databases as well as general internet searches in Google using search terms specific to individual rare diseases (for example, progeria) and names of methods (for example, response adaptive randomization) identified in the database searches. Finally, we mined the reference lists of qualifying articles to supplement our search.

\section{Article selection}

We combined the results of each search strategy and removed duplicates. One author (LT) screened titles and abstracts to exclude those articles that were clearly not relevant. Another author (JJG) conducted a second stage screening of those articles that passed the title and abstract screens. We included articles covering randomized trial design and analysis methods and methods for conducting observational research. Articles relating to other facets of rare diseases and their treatments (for example, those related to clinical practice or policy) were excluded.

\section{Data extraction}

We extracted descriptive information about each article, including information on the authors, title, and publication. If the article focused on a specific rare disease, we extracted the name of the condition. We then summarized the unique methods proposed or used in each article to study patient health outcomes in rare diseases. If the article presented an empirical application of an innovative method, we extracted the study's objective, the number of participants, the description of the method, and the description of the outcome.

For the qualitative synthesis, we classified novel research methods relating to the study of rare diseases into two broad categories: advances in clinical trial design for patients with rare diseases, and methods for observational studies of health outcomes in rare diseases. In each category we highlighted the most innovative research methodologies, and, where possible, provided examples of their applications.

\section{Results}

We identified 5346 records through our search process. After removing duplicates and performing an initial title screening to exclude those that were clearly irrelevant to our review, we identified 442 potentially relevant articles and, after the subsequent two stage screening process, we obtained full text versions of 55 articles. Of these, 46 proposed or employed methods for studying patient health outcomes in rare diseases (figure $\Downarrow$ ). Articles covered a wide range of rare diseases, from amyotrophic lateral sclerosis to multiple myeloma to uveal melanoma. Of the 13 articles that involved an empirical application, the number of participants ranged from 23 to 4980 . Most of the articles (33/46, 70\%) were published between 2008 and 2012. Table $1 \Downarrow$ presents a summary of the research methods we identified and their advantages in the setting of research into rare diseases.

\section{Clinical trial designs used in patients with rare diseases}

Conventional parallel group randomized controlled trials, which randomly allocate participants to one of two or more treatment groups, are not always feasible in rare conditions. ${ }^{6} \mathrm{We}$ found 19 articles proposing or employing novel clinical trial methods for studying therapeutic interventions in rare diseases. These approaches were classified into two groups: designs that minimize the total number of participants, and designs that maximize the number of on-treatment participants.

\section{Minimizing trial sample size}

Investigators studying rare diseases have tried to deal with the small pool of potential trial participants. Some proposed or made adjustments to traditional randomized trials. For example, when considering the treatment period, choosing a longer trial duration can reduce sample size requirements by capturing more events among the trial participants. ${ }^{7}$ Focusing on high risk patients can reduce sample size and study duration, ${ }^{8}$ and using genetic testing can reduce variability between individuals and allow inclusion of patients before they experience symptoms. ${ }^{9}$ Finally, some investigators have sought to reduce sample size by tackling multiple treatment options in a factorial study, in which two (or more) treatment comparisons are carried out simultaneously. ${ }^{10}$ Factorial designs provide answers to multiple questions within the same study population. This reduces the total number of patients required to answer all of the questions of interest but does not reduce the number of patients required to answer each individual question.

Another way to reduce sample size requirements in rare disease studies is through selection of the outcome measure using a continuous outcome variable, a surrogate marker, a composite endpoint, or repeated measure outcome. Identifying a continuous outcome variable, rather than a binary measure, can enhance statistical efficiency. ${ }^{7}$ For example, percentage reduction in a continuous measurement imparts greater statistical power in an analysis than an outcome measurement based on the proportion of patients who attain some threshold in reduction of the measure, provided that the continuous outcome variable has a small variance. Surrogate endpoints, such as biomarkers, that predict whether patients will experience clinical outcomes of interest may also be useful, but validating biomarkers as good surrogates of the clinical outcome of interest can be difficult. They can further enhance statistical power since a potentially small number of patients in a study experience the hard endpoint of interest, whereas nearly all patients have measured values of the biomarker. ${ }^{71}$ When hard clinical endpoints are preferred, combining multiple outcomes into a single composite outcome measure can increase the number of observed events and thus the statistical power. ${ }^{12}$ Repeated outcome measurements permit patients to contribute more than one outcome event or measurement, which also increases study power, allowing more precise estimation of variance between patients while permitting estimation of the variance within patients. ${ }^{12}$

A third approach to the sample size problem is to build networks to allow broader access to trials. Development of clinical trial networks for rare diseases can facilitate the conduct of multicenter and even multinational randomized trials. ${ }^{13}$ Trial networks facilitate the recruitment of larger and more geographically diverse patient populations than may be permitted by single center studies. ${ }^{14}$ The existence of such 
networks can also decrease the time required to complete a trial. ${ }^{14}$ For example, Goss and colleagues provide a comprehensive overview of clinical trial networks for rare diseases in the context of the Cystic Fibrosis Therapeutics Development Network. ${ }^{14}$

Finally, we found investigators who proposed and used novel trial design strategies to account for small pools of patients with rare diseases. Trials featuring an "adaptive design" allow modification of some aspects of the trial based on prospectively planned interim data analyses. The two basic types of adaptive designs are adaptive randomization and sequential trials. In trials using adaptive randomization, the probability of being randomized to an intervention changes during the enrollment period. The goal of adaptive randomization may be to minimize imbalance in baseline covariates among treatment groups (covariate-adaptive randomization) or to increase the proportion of patients assigned to the seemingly more effective treatment while reducing overall trial enrollment (response-adaptive randomization). By contrast, in sequential trials, data are analyzed intermittently to guide decisions on termination when safety concerns, futility, efficacy, or a combination of these factors is demonstrated. Trials that are stopped early because of important interim results require fewer patients. However, to control for multiple testing, trials that are not stopped early generally require larger sample sizes compared with similarly designed non-sequential trials. Chow and colleagues, Gupta and colleagues, and Cornu and colleagues have all summarized adaptive and sequential design methods in clinical trials and provide examples of applications to rare diseases. ${ }^{15-17}$ Gupta and colleagues also provide a framework for selecting among these approaches for studies of rare diseases.

Many variants of adaptive randomization and sequential designs are applicable to studying rare diseases because they can reduce the sample size required for conventional trials. In addition, certain adaptive designs can also increase participants' probability of receiving the most effective treatment, which can encourage enrollment in a trial. ${ }^{711} 12151618$ The decision about whether to use an adaptive design involves considering whether a set sample size can be reasonably recruited, the number of therapeutic options to be compared, and whether preliminary data suggest one treatment is superior. ${ }^{16}$ Cornu and colleagues proposed an algorithm for choosing an experimental design for small randomized clinical trials that also involves judging whether the outcome is reversible, whether the treatment response is likely to be rapid, and whether investigators seek to minimize the time participants are receiving placebo. ${ }^{17}$

Even if investigators use one of these innovative designs or adaptations of traditional trials in studying a rare disease treatment, individual trials of patient health outcomes may not be capable of attaining sufficient power to reject the null hypothesis using a conventional frequentist threshold $(\alpha=0.05)$. One solution is to increase $\alpha$, as was done in the alternating design trial of itraconazole by Gallin and colleagues. ${ }^{19}$ Another solution is to conduct the underpowered study and incorporate the results into a prospectively planned meta-analysis. ${ }^{18} 2021 \mathrm{~A}$ third option is to incorporate the results into a bayesian framework. Lilford and colleagues recommend the third approach for trials in rare diseases in which the individual trials are unlikely to result in a definitive answer but each can change the level of certainty around the clinical question. ${ }^{22}$ The bayesian approach uses all available data - from the trial and other sources-to calculate probabilities that a particular treatment is effective. These probabilities can then be applied to clinical practice. Bayesian methods can also be useful in individual studies (randomized controlled trials and observational) of health outcomes in rare diseases. ${ }^{11}$

Tan and colleagues described a bayesian approach to combining previous data with data from a new randomized controlled trial by creating scores that are then used to weight the pieces of evidence according to their pertinence, validity, and precision. ${ }^{23}$ The validity scores enable investigators to down-weight evidence based on studies with flaws or other concerns, such as confounding in non-randomized trials. Pertinence scores are based on how closely the information from each source relates to the information to be gained in the trial. In theory, pertinence scores could also be based on the degree to which the evidence streams are relevant to patients' decision making and could therefore support patient centered decision making. The authors make the case that such a bayesian approach can increase the robustness of information from small trials and can be used to help design and provide justification for such trials. However, bayesian approaches require appropriate specification of a prior distribution, which may be subjective or based on limited information.

\section{Maximizing on-treatment participants}

Trials that guarantee participants receive an intervention can enhance recruitment for patients with rare diseases who have limited treatment options. Some of these designs can also reduce recruitment requirements compared with alternative conventional parallel group randomized controlled trials. For example, crossover trials involve randomizing patients to treatment at one time (or several times) and to no treatment (or treatment with a comparator) at another time (or other times). ${ }^{1012} 13162324$ In addition to guaranteeing treatment, crossover designs are more statistically efficient than their parallel group randomized controlled trial counterparts. Crossover trials are particularly well suited to studying treatments for chronic conditions in which the treatments provide immediate relief of symptoms. But crossover trials generally cannot be used to study treatments that have curative effects or conditions that are rapidly changing. Many rare diseases are chronic conditions that progress over time. Changes in the disease over time that are unrelated to the treatment under study can cause bias in crossover trials. Crossover trials also require a transient treatment effect to minimize carryover effects into the subsequent treatment periods.

In the most basic crossover design involving two treatments, patients are randomly assigned to one treatment, followed by a washout period, and then receive a different treatment. Other patients are randomized to the reverse ordering. More complex crossover studies include so called alternating designs, in which patients are randomly assigned to each treatment at multiple time points. ${ }^{25}$ Gallin and colleagues conducted a randomized crossover trial to examine itraconazole for fungal infections in patients with chronic granulomatous disease. ${ }^{19}$ Given the rarity of this disease, it took 10 years to enroll only 39 patients. The investigators randomly assigned patients to receive itraconazole or placebo for one year and then to alternate annually between itraconazole and placebo. While this approach could not provide much information on the long term safety of itraconazole treatment, the multiple observations that each patient contributed made it possible to achieve sufficient statistical power (defined as a two sided type I error probability of 0.10 ) with only 39 participants. ${ }^{25}$

An n-of-1 study is a special type of crossover design in which the trial comprises one patient. ${ }^{10-13} 162324$ Within clinical practice settings, healthcare providers administer a treatment and a 
control at randomly determined times and observe subsequent outcomes. These trials require the same general assumptions as crossover trials. While statistical inference cannot be made based on a single n-of- 1 trial, results of multiple such studies can be aggregated in case series or even meta-analyzed quantitatively. ${ }^{26}$ Investigators in the Netherlands are developing an n-of-1 trial service integrated in the Dutch healthcare system to generate evidence on the efficacy of treatments for rare neuromuscular diseases. ${ }^{27}$ It will involve testing treatments that are available on the market but not necessarily approved for the neuromuscular indications. The project will create protocols for each n-of-1 trial and will collect the data in an electronic registry system. Less common variants of crossover designs include the Latin square design, the stepped wedge design, and the randomized withdrawal design. ${ }^{17}$ Cornu and colleagues and Gupta and colleagues provide more detailed descriptions of the application of these clinical trial designs to studying treatments in rare diseases. ${ }^{16} 17$

\section{Methods for observational studies of health outcomes in rare diseases}

In addition to the often small samples, studies using observational data to assess patient health outcomes in rare diseases face important challenges. For example, there is often no appropriate comparison group against which to compare outcome frequencies in patients with rare diseases and even when there is, controlling for confounding can be difficult because the risk factors of those outcomes are usually not well understood. Table $2 \Downarrow$ summarizes methods that have been proposed or used to analyze health outcomes in patients with rare disease in observational data. These methods can be generally classified into four categories: advanced methods to tackle confounding, self controlled observational study designs, approaches for case-control studies, and prospective inception cohorts.

\section{Advanced methods to deal with confounding}

Some authors have suggested the use of certain advanced methods to tackle confounding in studies of rare disease health outcomes, such as propensity scores. ${ }^{28}{ }^{29}$ When comparing patients being treated for a particular rare disease to patients with the same disease but who are not being treated, confounding will occur if the determinants of one patient's receipt of treatment over another are also risk factors for the outcome of interest. Often, many such confounders can be present. Propensity scores reduce the dimensionality of confounding in observational studies by summarizing all potential confounders into a single scalar score. ${ }^{30}$ This tool is particularly useful in studies in which there are few outcome events relative to the number of confounders, which is a defining characteristic of rare diseases. ${ }^{31}$ In a study of a dose-response effect of enzyme replacement therapy in patients with Gaucher disease type 1, Grabowski and colleagues created propensity scores to summarize multiple confounders and then used the scores to match patients who received different doses of enzyme therapy. ${ }^{32}$ Though propensity scores can facilitate adjustment for many potential confounders by modeling the exposure rather than the outcome, neither propensity scores nor traditional outcome regression modeling can overcome confounding due to unmeasured variables.

\section{Self controlled observational study designs}

Self controlled observational designs may be useful in the rare disease setting. These approaches are observational analogues to the randomized crossover trials described above in which patients act as their own controls. These studies can be indexed by outcome, such as in case-crossover designs, ${ }^{33}$ in which the frequency of exposure is compared during different time points among those who develop the outcome. They can also be indexed by exposure, such as the self controlled case series, ${ }^{34}$ in which the frequency of outcome is compared during different time points among those exposed to the intervention of interest. Notable for patients with rare diseases, these approaches are immune to confounding by factors that do not change over time because of the within person comparisons. Similar to randomized self controlled trial designs, self controlled observational methods enhance statistical power and therefore reduce sample size requirements. Self controlled observational methods are subject to the same limitations as randomized self controlled trial designs but can also be susceptible to time varying confounding, such as when worsening of disease, which may be a risk factor for the outcome of interest, may also prompt treatment.

\section{Case-control designs}

Several observational studies of rare diseases have used a case-control design, which is particularly useful in settings in which outcomes are rare and require primary data collection methods. Case-control studies involve sampling from an underlying cohort of patients rather than utilizing information on all cohort patients, which can be resource prohibitive. Schmidt-Pokrzywniak and colleagues conducted an institutional based case-control study to examine risk factors for uveal melanoma ${ }^{35}$ Rather than using a full cohort approach, the authors recruited cases from a referral center for eye tumors and sampled controls from among the cases' siblings and from local ophthalmologists' case loads. The case-control design yields an estimate of the same effect estimate as if the entire underlying cohort were used, but with slightly less precision given the sampling. In addition to reducing sample size requirements by identifying all cases and sampling controls, the case-control design allows investigators to easily examine multiple risk factors related to the outcome of interest. In other articles, Schmidt-Pokrzywniak and colleagues have examined the relations between uveal melanoma and mobile phone use, occupational cooking, and ultraviolet radiation. ${ }^{36-38}$

Cole and colleagues conducted a case-control study using the International Collaborative Gaucher Group registry. ${ }^{28}$ The authors compared the odds of splenectomy in patients with avascular necrosis (cases) with the odds in patients without avascular necrosis (controls). The authors used risk set matching, which can reduce bias in case-control studies relative to other sampling strategies. In risk set matching, controls are sampled from sets of patients at risk for the outcome at the time of the corresponding case event. These sets are usually defined by calendar time but can be defined by other variables as well, such as age and sex.

\section{Prospective inception cohorts}

A fourth group of studies employed prospective inception cohort designs, which are also sometimes referred to as "new user" designs when cohort inception is defined by the start of some medical treatment. ${ }^{39}{ }^{40}$ Inception cohorts permit investigators to establish clear temporality among study variables (that is, baseline confounders, exposures, and outcomes) and capture outcome events that occur shortly after entry to the cohort. This approach is particularly important for outcomes related to medical interventions that may be immediately affected by those interventions. While inception cohorts increase validity of 
observational studies, they can be difficult to implement for rare diseases because they require restricting the already small patient population to those with an observable start of the exposure, risk factor, or disease of interest. Identifying patients at the onset of a rare disease can be challenging because there can be a long lag time associated with making accurate diagnoses for rare diseases. Thus, patients enrolling in registries and other data sources may have had the underlying condition and subsequent treatment for some time. In addition, identifying "new users" of medical treatments for rare diseases outside of clinical trials can be limited if a large proportion of patients with the disease participated in the trial and were exposed to the treatment. Bernard and colleagues described the design and implementation of institution based prospective inception cohort studies in pediatric thrombosis and stroke research. ${ }^{41}$

\section{Discussion}

In this review of methods that have been proposed for and used to study health outcomes in rare diseases, we identified a wide variety of non-traditional approaches. The majority of the identified articles were published in 2008 or later, highlighting the increasing interest in this area. Most articles also focused on innovations in methods for clinical trials intended to minimize the number of participants needed to meet the study goals or to maximize the proportion of participants who receive active treatment to encourage enrollment.

\section{Implications for randomized trials}

Advances in clinical trial design relevant to rare diseases are well developed, having been discussed in several technical articles and applied in many clinical scenarios. Cornu and colleagues provide examples of studies that have used each of 12 different randomized designs in the setting of rare diseases. ${ }^{17}$ They and Gupta and colleagues have also proposed frameworks to aid selection of randomized clinical trial methods for studying health outcomes in rare diseases. ${ }^{16}{ }^{17}$ Both algorithms pose similar questions to address whether the assumptions of crossover and n-of-1 trials are likely to hold, such as whether the intervention of interest has only a short term effect on the outcome. Gupta and colleagues' algorithm asks about whether sufficient numbers of patients are likely to be recruited for a given design and offers alternatives when this is not the case. Cornu and colleagues' algorithm explicitly asks about whether objectives of the study include minimizing the time patients are receiving placebo or ensuring that patients receive active treatment by the end of the trial. Until a unified framework is developed, both algorithms can be used to help decide the most appropriate design to study health outcomes in patients with rare diseases.

\section{Implications for observational studies}

In addition to dealing with considerations about general design and analysis (for example, outcome selection, incorporation of evidence into larger context), our methodological review is the first to go beyond randomized trial methods for studying rare diseases. This is important because in small sample sizes, randomization will not always achieve its goal of balancing patient characteristics between treatment groups. In contrast with the body of literature on clinical trial methods in rare diseases, however, the literature on observational methods is considerably less mature. Several observational studies presented only descriptive frequencies of outcomes after a treatment and often with no comparison group, limiting the inferences that can be drawn about the treatment and subsequent outcomes. In general, observational studies of rare diseases used the same methods that are used to study health outcomes in more common conditions. However, several advanced observational methods that are used to study outcomes in common

conditions-including propensity scores and self controlled designs-are particularly well suited for tackling confounding in the setting of rare events. Propensity scores deal with confounding in between person comparisons, whereas self controlled designs implicitly tackle time invariant confounding by making within person comparisons. It is important to note, however, that statistically controlling for confounding may not always be possible, even with propensity scores in studies with few participants.

In addition to the often small samples, studies of patient health outcomes in rare diseases using observational data face other important challenges. For example, there is often no appropriate group against which to compare outcome frequencies in patients with rare diseases and, even when there is, controlling for confounding can be difficult because the risk factors of those outcomes are usually not well understood. Yet, little work has been done to develop or apply methods to directly deal with these challenges. We did not identify any novel observational methods that have been developed to study outcomes in rare diseases. As observational data on rare diseases become more ubiquitous, greater attention is needed on methods to analyze these data to validly evaluate health outcomes in patients with rare diseases.

\section{Limitations of this study}

This survey of research methods for rare diseases has several limitations. Firstly, our literature search was focused on articles that mentioned "rare disease" in a searchable field. Because of the large number of unique rare diseases, we were not able to search for applications of innovative methods related to each specific disease. In addition, our review was intended to provide a general overview of non-traditional methods that have been proposed or applied to studying rare diseases. If other non-traditional methods exist that might be applicable to rare diseases but have not yet been discussed in a publication in the databases we searched, we may not have identified them.

Moreover, our review is intended to enhance awareness of the availability and use of innovative methods for studying health outcomes in rare diseases and is not intended to provide a technical review of these methods, which can be found in the cited references. Finally, while we searched three databases, two of which include biomedical journals and a third that covers disciplines including psychology, physics, and engineering, it is possible that we missed relevant methods that have been used in other specialties, such as the social sciences.

\section{Conclusions and future directions}

Despite these limitations, we found several promising strategies that may contribute substantial advances to the study of health outcomes in patients with rare diseases. Some of these methods (for example, crossover designs and propensity scores) are already used in studies of common conditions. Awareness of the armamentarium of research tools available will help investigators design studies in patients with specific rare diseases and will help clinicians interpret the results of these studies when treating patients with these conditions. Observational studies are an important approach for studying health outcomes in rare diseases, particularly as patient registries and electronic healthcare databases continue to grow and offer richer clinical information. However, greater attention to innovative methods 
for using observational data to study rare disease health outcomes is needed.

Contributors: JJG and ASK conceived and designed the study. JJG drafted the article. All authors analysed and interpreted the data, revised the manuscript for important intellectual content, gave final approval of the version to be published, and fulfill the criteria for authorship. No one who is not included as an author fulfills the criteria. JJG is the guarantor. Funding: This project was funded under Contract No $290201000006 \mathrm{l}$ TO \#4 from the Agency for Healthcare Research and Quality, US Department of Health and Human Services as part of the Developing Evidence to Inform decisions about Effectiveness (DEcIDE) program. The authors of this report are responsible for its content. Statements in the report should not be construed as endorsement by the Agency for Healthcare Research and Quality or the US Department of Health and Human Services.

Competing interests: All authors have completed the ICMJE uniform disclosure form at www.icmje.org/coi_disclosure.pdf (available on request from the corresponding author) and declare: support from the Agency for Healthcare Research \& Quality for the submitted work; no financial relationships with any organisations that might have an interest in the submitted work in the previous three years; no other relationships or activities that could appear to have influenced the submitted work.

Ethical approval: Not required.

Data sharing: Summary data are available from the corresponding author at jgagne1@partners.org.

Transparency: JJG affirms that the manuscript is an honest, accurate, and transparent account of the study being reported; that no important aspects of the study have been omitted; and that any discrepancies from the study as planned have been explained.

1 EURORDIS: European Organisation for Rare Diseases. Rare diseases: understanding this public health priority. 2005. www.eurordis.org/IMG/pdf/princeps_document-EN.pdf. Orphan Drug Act, Pub. L. No 97-414, 96 Stat. 2049 (1984 as amended).

3 National Center for Advanceing Translational Sciences. Office of Rare Disease Research. Frequently asked questions. 2013. http://rarediseases.info.nih.gov/about-ordr/pages/31/ frequently-asked-questions.

4 Kesselheim AS, Gagne JJ. Strategies for post-market surveillance of drugs for rare diseases. Clin Pharmacol Ther 2014;95:265-8.

5 De la Paz MP, Villaverde-Hueso A, Alonso V, János S, Zurriaga O, Pollán M, et al. Rare diseases epidemiology research. Adv Exp Med Biol 2010:686:17-39.

6 Kesselheim AS, Myers JA, Avorn J. Characteristics of clinical trials to support approval of orphan vs nonorphan drugs for cancer. JAMA 2011;305:2320-6.

7 Shurin S, Krischer J, Groft SC. Clinical trials In BMT: ensuring that rare diseases and rarer therapies are well done. Biol Blood Marrow Transplant 2012;18:S8-11.

8 Whitehead J, Tishkovskaya S, O'Connor J, Damato B. Devising two-stage and multistage phase II studies on systemic adjuvant therapy for uveal melanoma. Invest Ophthalmol Vis Sci 2012;53:4986-9.

9 Stone EM. Challenges in genetic testing for clinical trials of inherited and orphan retinal diseases. Retina 2005;25:S72-3.

10 Griggs RC, Batshaw M, Dunkle M, Gopal-Srivastava R, Kaye E, Krischer J, et al. Clinical research for rare disease: opportunities, challenges, and solutions. Mol Genet Metab 2009;96:20-6.

11 Buckley BM. Clinical trials of orphan medicines. Lancet 2008;371:2051-5.

12 Van der Lee JH, Wesseling J, Tanck MW, Offringa M. Efficient ways exist to obtain the optimal sample size in clinical trials in rare diseases. J Clin Epidemiol 2008;61:324-30.

13 Kinder B, McCormack FX. Clinical trials for rare lung diseases: lessons from lymphangioleiomyomatosis. Lymphat Res Biol 2010;8:71-9.

14 Goss $\mathrm{CH}$, Mayer-Hamblett N, Kronmal RA, Ramsey BW. The cystic fibrosis therapeutics development network (CF TDN): a paradigm of a clinical trials network for genetic and orphan diseases. Adv Drug Deliv Rev 2002;54:1505-28.

15 Chow SC, Chang M. Adaptive design methods in clinical trials-a review. Orphanet $J$ Rare Dis 2008;3:11

16 Gupta S, Faughnan ME, Tomlinson GA, Bayoumi AM. A framework for applying unfamiliar trial designs in studies of rare diseases. J Clin Epidemiol 2011;64:1085-94.

17 Cornu C, Kassai B, Fisch R, Chiron C, Alberti C, Guerrini R, et al. Experimental designs for small randomised clinical trials: an algorithm for choice. Orphanet J Rare Dis 2013;8:48.

18 Dimichele DM, Blanchette V, Berntorp E. Clinical trial design in haemophilia. Haemophilia 2012;18(Suppl 4):18-23.

19 Gallin JI, Alling DW, Malech HL, Wesley R, Koziol D, Marciano B, et al. Itraconazole to prevent fungal infections in chronic granulomatous disease. N Engl J Med 2003:348:2416-22

20 Puopolo M, Pocchiari M. Need to improve clinical trials in rare neurodegenerative disorders. Ann Ist Super Sanita 2011;47:55-9.
21 Halpern SD, Karlawish JH, Berlin JA. The continuing unethical conduct of underpowered clinical trials. JAMA 2002;288:358-62.

22 Lilford RJ, Thornton JG, Braunholtz D. Clinical trials and rare diseases: a way out of a conundrum. BMJ 1995;311:1621-5.

23 Tan SB, Dear KB, Bruzzi P, Machin D. Strategy for randomised clinical trials in rare cancers. BMJ 2003;327:47-9.

24 Hyman L. Design of phase III clinical trials for treatments of orphan retinal diseases: an overview of considerations. Retina 2005;25:S69-71.

25 Lagakos SW. Clinical trials and rare diseases. N Engl J Med 2003;348:2455-6.

26 Berlin JA. N-of-1 clinical trials should be incorporated into clinical practice. J Clin Epidemiol 2010;63:1283-4.

27 Weinreich SS, Vrinten C, Verschuuren JJGM, UyI-de Groot, CA, Kuijpers MR, Sterrenburg $\mathrm{E}$, et al. From rationing to rationality: an $\mathrm{n}$-of-one trial service for off-label medicines for rare (neuromuscular) diseases. Orphanet J Rare Dis 2012;7(Suppl 2):A29.

28 Cole JA, Taylor JS, Hangartner TN, Weinreb NJ, Mistry PK, Khan A. Reducing selection bias in case-control studies from rare disease registries. Orphanet $J$ Rare Dis 2011;6:61.

29 Sun P, Garrison LP. Retrospective outcomes studies for orphan diseases: challenges and opportunities. Curr Med Res Opin 2012;28:665-7.

30 Rosenbaum PR, Rubin DB. The central role of the propensity score in observational studies for causal effects. Biometrika 1983;70:41-55.

31 Cepeda MS, Boston R, Farrar JT, Strom BL. Comparison of logistic regression versus propensity score when the number of events is low and there are multiple confounders. Am J Epidemiol 2003;158:280-7.

32 Grabowski GA, Kacena K, Cole JA, Hollak CE, Zhang L, Yee J, et al. Dose-response relationships for enzyme replacement therapy with imiglucerase/alglucerase in patients with Gaucher disease type 1. Genet Med 2009;11:92-100.

33 Maclure $\mathrm{M}$. The case-crossover design: a method for studying transient effects on the risk of acute events. Am J Epidemiol 1991;133:144-53.

34 Farrington CP, Nash J, Miller E. Case series analysis of adverse reactions to vaccines: a comparative evaluation. Am J Epidemiol 1996;143:1165-73.

35 Schmidt-Pokrzywniak A, Jockel KH, Bornfeld N, Stang A. Case-control study on uvea melanoma (RIFA): rational and design. BMC Ophthalmol 2004;4:11.

36 Schmidt-Pokrzywniak A, Jockel KH, Bornfeld N, Sauerwein W, Stang A. Positive interaction between light iris color and ultraviolet radiation in relation to the risk of uveal melanoma: a case-control study. Ophthalmology 2009;116:340-8

37 Schmidt-Pokrzywniak A, Jockel KH, Marr A, Bornfeld N, Stang A. A case-control study: occupational cooking and the risk of uveal melanoma. BMC Ophthalmol 2010;10:26.

38 Stang A, Schmidt-Pokrzywniak A, Lash TL, Lommatzsch PK, Taubert G, Bornfeld N, et al. Mobile phone use and risk of uveal melanoma: results of the risk factors for uveal melanoma case-control study. J Natl Cancer Inst 2009;101:120-3.

39 Ray WA. Evaluating medication effects outside of clinical trials: new-user designs. Am J Epidemiol 2003;158:915-20.

40 Armstrong-Wells J, Goldenberg NA. Institution-based prospective inception cohort studies in neonatal rare disease research. Semin Fetal Neonatal Med 2011;16:355-8.

41 Bernard TJ, Armstrong-Wells J, Goldenberg NA. The institution-based prospective inception cohort study: design, implementation, and quality assurance in pediatric thrombosis and stroke research. Semin Thromb Hemost 2013;39:10-4.

42 Nakamura C, Bromberg M, Bhargava S, Wicks P, Zeng-Treitler Q. Mining online social network data for biomedical research: a comparison of clinicians' and patients' perceptions about amyotrophic lateral sclerosis treatments. J Med Internet Res 2012;14:e90.

43 Wicks P, Vaughan TE, Massagli MP, Heywood J. Accelerated clinical discovery using self-reported patient data collected online and a patient-matching algorithm. Nat Biotechnol 2011;29:411-4.

44 Barash JA, Desai RA, Patwa HS. Veterans health administration information systems as a resource for rare disorders research: Creutzfeldt-Jakob disease as a paradigm. Mil Med 2012;177:1343-7.

45 Schick U, Bolukbasi Y, Thariat J, Abdah-Bortnyak R, Kuten A, Igdem S, et al. Outcome and prognostic factors in endometrial stromal tumors: a Rare Cancer Network study. Int $J$ Radiat Oncol Biol Phys 2012;82:e757-63.

46 Pugnet G, Sailler L, Bourrel R, Sommet A, Montastruc JL, Lapeyre-Mestre M. Pharmacoepidemiology as an opportunity for prognostic studies in rare diseases: the example of giant cell arteritis and the French APOGEE cohort (Arterite en Population Generale). Basic Clin Pharmacol Toxicol 2010;10:533.

47 McCann LJ, Juggins AD, Maillard SM, Wedderburn, LR, Davidson JE, Murray KJ, et al. The Juvenile Dermatomyositis National Registry and Repository (UK and Ireland)—clinical characteristics of children recruited within the first 5 yr. Rheumatology (Oxford) 2006;45:1255-60.

48 Ozsahin M, Gruber G, Olszyk O, Karakoyun-Celik O, Pehlivan B, Azria D, et al. Outcome and prognostic factors in olfactory neuroblastoma: a rare cancer network study. Int $J$ Radiat Oncol Biol Phys 2010;78:992-7.

49 Fasnacht MS, Tolsa JF, Beghetti M. The Swiss registry for pulmonary arterial hypertension: the paediatric experience. Swiss Med Wkly 2007;137:510-3.

50 Sun P, Krueger D, Liu J, Guo A, Rogerio J, Kohrman M. Surgical resection of subependymal giant cell astrocytomas (SEGAs) and changes in SEGA-related conditions: a US national claims database study. Curr Med Res Opin 2012;28:651-6.

51 Sun P, Kohrman M, Liu J, Guo A, Rogerio J, Krueger D. Outcomes of resecting subependymal giant cell astrocytoma (SEGA) among patients with SEGA-related tuberous sclerosis complex: a national claims database analysis. Curr Med Res Opin 2012;28:657-63.

Accepted: 4 November 2014

\section{Cite this as: BMJ 2014;349:96802}

This is an Open Access article distributed in accordance with the Creative Commons Attribution Non Commercial (CC BY-NC 4.0) license, which permits others to distribute, remix, adapt, build upon this work non-commercially, and license their derivative works on different terms, provided the original work is properly cited and the use is non-commercial. See: http://creativecommons.org/licenses/by-nc/4.0/. 


\section{What is already known on this topic}

Many barriers exist to advancing knowledge of and treatment options for rare diseases

Because rare diseases are clinically dissimilar, clinicians, scientists, and other stakeholders working in one medical specialty may not be familiar with methods being applied in other disciplines

\section{What this study adds}

Several promising strategies that may contribute substantial advances to the study of health outcomes in patients with rare diseases have been proposed, particularly for randomized trials

Greater attention to innovative methods for using observational data to study rare disease health outcomes is needed

\section{Tables}

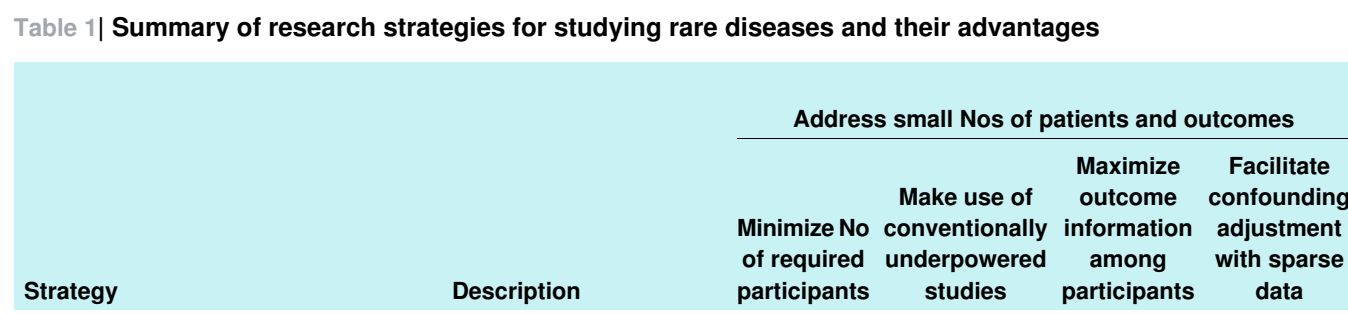

Promote recruitment and retention

Maximize No

of Expand

participants access to

Strategy

Description

participants

studies participants data

who receive studies and

treatment participants

Study design options:

\begin{tabular}{|c|c|c|c|c|c|c|c|}
\hline Factorial designs & $\begin{array}{l}\text { Two or more treatments can be } \\
\text { simultaneously compared in a single group } \\
\text { of study participants }\end{array}$ & $x$ & - & - & - & - & - \\
\hline $\begin{array}{l}\text { Response-adaptive } \\
\text { randomization }\end{array}$ & $\begin{array}{l}\text { Increases participants' probability of being } \\
\text { exposed to more effective treatment and } \\
\text { reduces total sample size }\end{array}$ & $x$ & - & - & - & $x$ & - \\
\hline Sequential designs & $\begin{array}{l}\text { Can identify differences in treatments } \\
\text { before the end of planned enrollment }\end{array}$ & $x$ & - & - & - & - & - \\
\hline $\begin{array}{l}\text { Crossover, } n \text {-of- } 1 \text {, } \\
\text { alternating designs }\end{array}$ & $\begin{array}{l}\text { Using patients as their own controls both } \\
\text { guarantees treatment and increases } \\
\text { statistical efficiency }\end{array}$ & $x$ & - & - & $x$ & $x$ & - \\
\hline Use continuous outcome & $\begin{array}{l}\text { As compared with binary outcome, } \\
\text { continuous measures increase statistical } \\
\text { efficiency }\end{array}$ & - & - & $x$ & - & - & - \\
\hline Use surrogate outcome & $\begin{array}{l}\text { Can be measured before patients are lost } \\
\text { to follow-up for hard clinical endpoints }\end{array}$ & - & - & $x$ & - & - & - \\
\hline Use composite outcome & $\begin{array}{l}\text { Combining multiple outcomes into a single } \\
\text { endpoint increases number of events }\end{array}$ & - & - & $x$ & - & - & - \\
\hline $\begin{array}{l}\text { Use repeated measure } \\
\text { outcome }\end{array}$ & $\begin{array}{l}\text { Allowing patients to contribute more than } \\
\text { one event can increase total number of } \\
\text { events }\end{array}$ & - & - & $x$ & - & - & - \\
\hline $\begin{array}{l}\text { Increase duration of } \\
\text { follow-up }\end{array}$ & $\begin{array}{l}\text { Longer studies permit capture of more } \\
\text { outcome events among participants }\end{array}$ & - & - & $x$ & - & - & - \\
\hline Case-control sampling & $\begin{array}{l}\text { Reduces study size by sampling a portion } \\
\text { of patients who do not experience an } \\
\text { outcome }\end{array}$ & - & - & - & - & - & - \\
\hline \multicolumn{8}{|l|}{$\begin{array}{l}\text { Recruitment and } \\
\text { enrollment strategies: }\end{array}$} \\
\hline $\begin{array}{l}\text { Focus on high risk } \\
\text { patients }\end{array}$ & $\begin{array}{l}\text { Outcomes are more likely to occur in high } \\
\text { risk patients }\end{array}$ & - & - & $x$ & - & - & - \\
\hline $\begin{array}{l}\text { Trial networks and } \\
\text { distributed data networks }\end{array}$ & $\begin{array}{l}\text { Infrastructure for multicenter studies can } \\
\text { permit recruitment of larger and } \\
\text { geographically diverse groups of patients }\end{array}$ & - & - & - & - & - & $x$ \\
\hline \multicolumn{8}{|l|}{ Statistical options: } \\
\hline Increase a & $\begin{array}{l}\text { Small patient populations may preclude } \\
\text { sample sizes with sufficient power to } \\
\text { detect effects using conventional } \\
\text { thresholds }\end{array}$ & - & $x$ & - & - & - & - \\
\hline
\end{tabular}
thresholds 
Table 1 (continued)

\begin{tabular}{|c|c|c|c|c|c|c|c|}
\hline \multirow[b]{2}{*}{ Strategy } & \multirow[b]{2}{*}{ Description } & \multicolumn{4}{|c|}{ Address small Nos of patients and outcomes } & \multicolumn{2}{|c|}{$\begin{array}{c}\text { Promote recruitment and } \\
\text { retention }\end{array}$} \\
\hline & & $\begin{array}{l}\text { Minimize No } \\
\text { of required } \\
\text { participants }\end{array}$ & $\begin{array}{c}\text { Make use of } \\
\text { conventionally } \\
\text { underpowered } \\
\text { studies }\end{array}$ & $\begin{array}{c}\text { Maximize } \\
\text { outcome } \\
\text { information } \\
\text { among } \\
\text { participants }\end{array}$ & $\begin{array}{c}\text { Facilitate } \\
\text { confounding } \\
\text { adjustment } \\
\text { with sparse } \\
\text { data }\end{array}$ & $\begin{array}{c}\text { Maximize No } \\
\text { of } \\
\text { participants } \\
\text { who receive } \\
\text { treatment }\end{array}$ & $\begin{array}{c}\text { Expand } \\
\text { access to } \\
\text { studies and } \\
\text { participants }\end{array}$ \\
\hline Propensity scores & $\begin{array}{l}\text { Can permit adjustment for more potential } \\
\text { confounders than outcome regression } \\
\text { modeling }\end{array}$ & - & - & - & $x$ & - & - \\
\hline \multicolumn{8}{|l|}{$\begin{array}{l}\text { Incorporation into larger } \\
\text { evidence context: }\end{array}$} \\
\hline $\begin{array}{l}\text { Conduct study as part of } \\
\text { prospectively planned } \\
\text { meta-analysis }\end{array}$ & $\begin{array}{l}\text { Individual small studies may not provide } \\
\text { definitive evidence about a question, but } \\
\text { can be combined to yield sufficient power }\end{array}$ & - & $x$ & - & - & - & - \\
\hline $\begin{array}{l}\text { Incorporate study into } \\
\text { bayesian framework }\end{array}$ & $\begin{array}{l}\text { Small studies can help increase the } \\
\text { certainty around a clinical question }\end{array}$ & - & $x$ & - & - & - & - \\
\hline
\end{tabular}




\begin{tabular}{|c|c|c|c|c|c|}
\hline $\begin{array}{l}\text { Lead author, } \\
\text { reference No }\end{array}$ & Rare condition & Study objective & $\begin{array}{c}\text { No of } \\
\text { patients }\end{array}$ & Outcome & Methodological approach \\
\hline Nakamura $^{42}$ & $\begin{array}{l}\text { Amyotrophic lateral } \\
\text { sclerosis (ALS) }\end{array}$ & $\begin{array}{l}\text { Compare clinicians' and patients' } \\
\text { perspectives on symptomatic treatment }\end{array}$ & 4375 & $\begin{array}{l}\text { Concordance between patient } \\
\text { and clinician perceptions }\end{array}$ & $\begin{array}{l}\text { Used patient reported perceptions of } \\
\text { drug effectiveness for ALS symptoms } \\
\text { and compared this with survey based } \\
\text { physician perceptions }\end{array}$ \\
\hline Wicks $^{43}$ & ALS & $\begin{array}{l}\text { Investigate whether off-label treatment } \\
\text { with lithium slows disease progression of } \\
\text { disease }\end{array}$ & 447 & $\begin{array}{l}\text { Change in the revised ALS } \\
\text { functional rating scale }\end{array}$ & $\begin{array}{l}\text { Matched lithium users to non-users and } \\
\text { followed for improvements in disease } \\
\text { progression }\end{array}$ \\
\hline Barash $^{44}$ & $\begin{array}{l}\text { Creutzfeldt-Jakob } \\
\text { disease }\end{array}$ & $\begin{array}{l}\text { Determine incidence of Creutzfeldt-Jakob } \\
\text { disease in Veterans Health Administration } \\
\text { and describe clinical features }\end{array}$ & 115 & $\begin{array}{l}\text { Incidence and clinical features } \\
\text { of Creutzfeldt-Jakob disease }\end{array}$ & $\begin{array}{l}\text { Used linked electronic information } \\
\text { system to study outcomes in patients } \\
\text { with rare diseases }\end{array}$ \\
\hline Schick ${ }^{45}$ & $\begin{array}{l}\text { Endometrial stromal } \\
\text { cancers }\end{array}$ & $\begin{array}{l}\text { Assess rates, time, and sites of } \\
\text { recurrence for patients with endometrial } \\
\text { stromal sarcomas }\end{array}$ & 66 & $\begin{array}{l}\text { Overall survival, disease-free } \\
\text { survival, locoregional control }\end{array}$ & $\begin{array}{l}\text { Used descriptive statistics, } \\
\text { Kaplan-Meier plot, and multivariable } \\
\text { time to event model }\end{array}$ \\
\hline Cole $^{28}$ & Gaucher disease & $\begin{array}{l}\text { Compare odds of splenectomy in patients } \\
\text { with and without avascular necrosis }\end{array}$ & 4980 & Splenectomy & $\begin{array}{l}\text { Proposed risk-set matching to reduce } \\
\text { selection bias in case-control studies }\end{array}$ \\
\hline Pugnet $^{46}$ & Giant cell arteritis & $\begin{array}{l}\text { Examine incidence and predictors of } \\
\text { corticosteroid withdrawal in giant cell } \\
\text { arteritis }\end{array}$ & 103 & Corticosteroid withdrawal & $\begin{array}{l}\text { Proposed use of claims data for } \\
\text { observational studies in rare diseases }\end{array}$ \\
\hline McCann ${ }^{47}$ & $\begin{array}{l}\text { Juvenile } \\
\text { dermatomyositis }\end{array}$ & $\begin{array}{l}\text { Identify epidemiological, clinical, and } \\
\text { laboratory characteristics of juvenile } \\
\text { dermatomyositis }\end{array}$ & 122 & $\begin{array}{l}\text { Patient characteristics, clinical } \\
\text { features over time, and drug } \\
\text { use over time }\end{array}$ & $\begin{array}{l}\text { Prospectively measured disease } \\
\text { activity and patient reported health } \\
\text { outcomes }\end{array}$ \\
\hline Ozsahin ${ }^{48}$ & $\begin{array}{l}\text { Olfactory } \\
\text { neuroblastoma }\end{array}$ & $\begin{array}{l}\text { Assess outcomes in patients with } \\
\text { olfactory neuroblastoma }\end{array}$ & 77 & $\begin{array}{l}\text { Overall survival, disease-free } \\
\text { survival, locoregional and local } \\
\text { control }\end{array}$ & $\begin{array}{l}\text { Used descriptive statistics, } \\
\text { Kaplan-Meier plot, and multivariable } \\
\text { time to event model }\end{array}$ \\
\hline Fasnacht ${ }^{49}$ & $\begin{array}{l}\text { Pulmonary arterial } \\
\text { hypertension }\end{array}$ & $\begin{array}{l}\text { Describe characteristics of patients in } \\
\text { Swiss pulmonary arterial hypertension } \\
\text { registry }\end{array}$ & 23 & $\begin{array}{l}\text { Patient characteristics, clinical } \\
\text { features over time, and drug } \\
\text { use over time }\end{array}$ & $\begin{array}{l}\text { Described clinical course with respect } \\
\text { to changes in clinical features and } \\
\text { treatments }\end{array}$ \\
\hline Sun $^{50}$ & $\begin{array}{l}\text { Subependymal giant } \\
\text { cell astrocytomas }\end{array}$ & $\begin{array}{l}\text { Compare prevalence of clinical conditions } \\
\text { related to disease of interest before and } \\
\text { after surgery among patients with } \\
\text { tuberous sclerosis complex }\end{array}$ & 47 & $\begin{array}{l}\text { Change in prevalence of } 20 \\
\text { different conditions }\end{array}$ & $\begin{array}{l}\text { Used } \\
\text { pre-observational/post-observational } \\
\text { design }\end{array}$ \\
\hline $\operatorname{Sun}^{51}$ & $\begin{array}{l}\text { Subependymal giant } \\
\text { cell astrocytomas }\end{array}$ & $\begin{array}{l}\text { Examine outcomes after resection of } \\
\text { disease of interest among patients with } \\
\text { tuberous sclerosis complex }\end{array}$ & 47 & $\begin{array}{l}\text { Diagnosis, repeated surgeries, } \\
\text { surgical complications }\end{array}$ & $\begin{array}{l}\text { Described outcomes in patients after } \\
\text { surgery }\end{array}$ \\
\hline
\end{tabular}




\section{Figure}

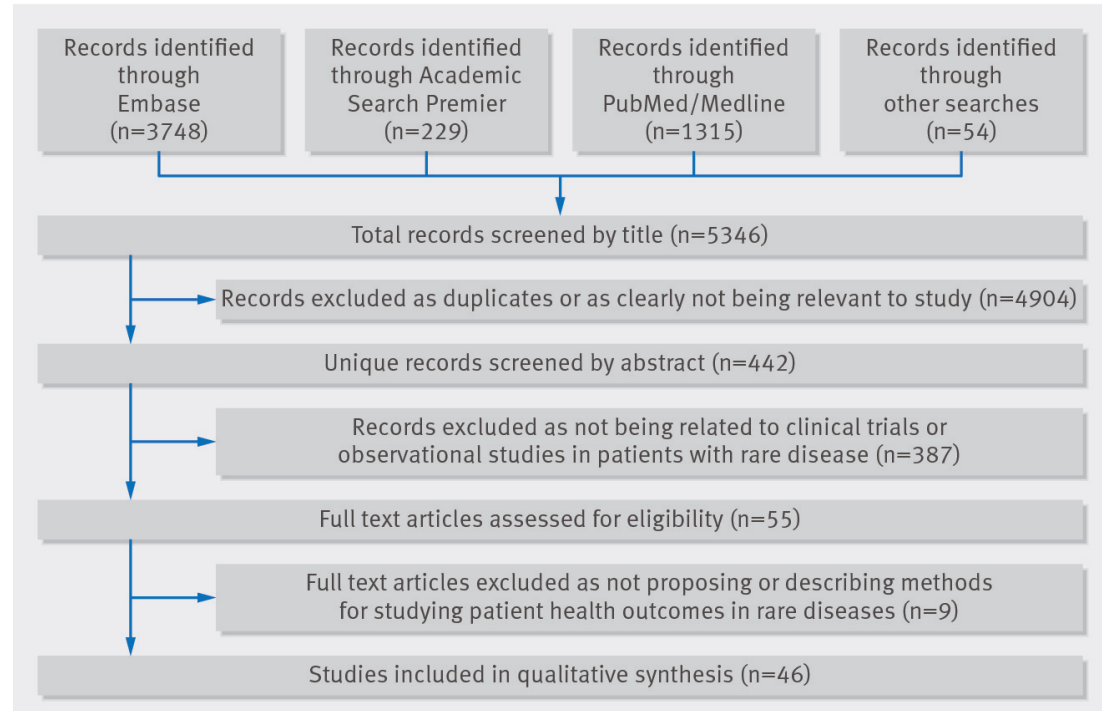

PRISMA flow diagram 